\title{
Fine map of the Gct1 spontaneous ovarian granulosa cell tumor locus
}

\author{
Kerri N. Smith • Sarah J. Halfyard • \\ Edward S. Yaskowiak • Kathryn L. Shultz • \\ Wesley G. Beamer · Ann M. Dorward
}

Received: 25 July 2012/ Accepted: 8 October 2012/Published online: 18 November 2012

(C) The Author(s) 2012. This article is published with open access at Springerlink.com

\begin{abstract}
The spontaneous development of juvenileonset, ovarian granulosa cell (GC) tumors in the SWR/Bm (SWR) inbred mouse strain is a model for juvenile-type GC tumors that appear in infants and young girls. GC tumor susceptibility is supported by multiple Granulosa cell tumor (Gct) loci, but the Gctl locus on Chr 4 derived from SWR strain background is fundamental for GC tumor development and uniquely responsive to the androgenic precursor dehydroepiandrosterone (DHEA). To resolve the location of Gctl independently from other susceptibility loci, Gctl was isolated in a congenic strain that replaces the distal segment of Chr 4 in SWR mice with a $47 \times 10^{6}$-bp genomic segment from the Castaneus/Ei (CAST) strain. SWR females homozygous for the CAST donor segment were confirmed to be resistant to DHEA- and testosteroneinduced GC tumorigenesis, indicating successful exchange of CAST alleles $\left(G c t 1^{C A}\right)$ for SWR alleles $\left(G c t 1^{S W}\right)$ at this tumor susceptibility locus. A series of nested, overlapping, congenic sublines was created to fine-map Gctl based on GC tumor susceptibility under the influence of pubertal DHEA treatment. Twelve informative lines have resolved
\end{abstract}

Electronic supplementary material The online version of this article (doi:10.1007/s00335-012-9439-6) contains supplementary material, which is available to authorized users.

K. N. Smith · S. J. Halfyard · E. S. Yaskowiak ·

A. M. Dorward $(\bowtie)$

Division of BioMedical Sciences, Faculty of Medicine,

Memorial University of Newfoundland, St. John's,

NL A1B 3V6, Canada

e-mail: ann.dorward@mun.ca

K. N. Smith

e-mail: kerri.smith@mun.ca

K. L. Shultz · W. G. Beamer

The Jackson Laboratory, Bar Harbor, ME 04609, USA the Gctl locus to a $1.31 \times 10^{6}$-bp interval on mouse $\mathrm{Chr} 4$, a region orthologous to human $\mathrm{Chr} 1 \mathrm{p} 36.22$.

\section{Introduction}

Human granulosa cell (GC) tumors are sex cord-stromal ovarian tumors that are divided into two clinicopathologic subtypes, adult-type and juvenile-type, based historically on histology and age at tumor diagnosis. Adult-type GC tumors are the more common subtype and typically occur in peri- and postmenopausal women (Björkholm and Silfverswärd 1981). Juvenile-type GC tumors can appear in girls from the time of infancy through adolescence and present immediate endocrinological and reproductive complications in addition to malignant potential (Young et al. 1984). A significant advance in our understanding of the GC tumorigenic mechanism has come with the introduction of high-throughput sequencing technology and the identification of a somatic missense mutation (p.C134W) in the FOXL2 gene that is common and specific for adult-type GC tumors (Shah et al. 2009; Al-Agha et al. 2011). The FOXL2 somatic mutation is not strongly associated with the juvenile subtype, suggesting alternate pathways for tumorigenic initiation in the juvenile-onset cases. The development of spontaneous juvenile-onset GC tumors in females of the SWR/Bm (hereafter SWR) inbred mouse strain is a model genetic system to identify pathways leading to juvenile-onset GC tumorigenesis.

The SWR inbred mouse strain and related recombinant inbred (RI) strains are unique for their heritable and spontaneous GC tumor phenotype that affects $1-25 \%$ of the young female population, depending on strain background and hormonal stimulation (Beamer et al. 1985). In affected females, GC tumors develop during a restricted initiation 
window that coincides with puberty (3-4 weeks of age) as preneoplastic blood-filled follicles that are macroscopically visible on the ovarian surface (Tennent et al. 1990). By 6-8 weeks of age, the tumors progress to highly vascularized cystic or hemorrhagic masses that are homogeneously composed of GCs and enclosed within the ovarian bursa (Beamer et al. 1985; Tennent et al. 1990). Those females that progress through the pubertal transition unaffected remain tumor-free, retain fertility with average litter sizes, and age normally without significant predisposition for the development of other primary tumors. Those females with initially benign proliferative tumors have a high risk for development of malignant disease, with a time course for progression between 6 and 10 months of age (Beamer et al. 1985; Tennent et al. 1990).

The mouse GC tumors are endocrinologically active, secreting high levels of estrogen and inhibin (Beamer et al. 1988a; Gocze et al. 1997), similar to their human juvenile GC tumor counterparts (Young et al. 1984; Sivasankaran et al. 2009). Spontaneous GC tumor initiation in SWR mice is also endocrine-sensitive, as demonstrated by tumor grafting studies that have determined that an intact hypothalamic-pituitary-gonadal axis is required for GC tumor development (Beamer et al. 1993). In the intact SWR female mouse, tumor frequency is significantly increased from $<1$ to $\geq 20 \%$ with exogenous androgen supplementation such as dehydroepiandrosterone (DHEA) and testosterone (Beamer et al. 1988a, b; Tennent et al. 1993; Dorward et al. 2007). In accordance with the lack of spontaneous GC tumor development outside the restricted susceptibility window, postpubertal treatment with these hormones does not stimulate GC tumor initiation (Beamer et al. 1993). Furthermore, short-term exposure to $17 \beta$-estradiol before, but not after, the appearance of preneoplastic follicular lesions suppresses GC tumor incidence (Dorward et al. 2007), indicating that the window of tumor initiation overlaps with that of tumor prevention in the mouse model. The restricted pubertal window also suggests that the first wave of maturing follicles have a distinct response to endocrine stimulation relative to subsequent waves of maturing follicles. A recent report by Mork et al. (2012) describes temporal differences in GC specification in the embryonic ovary, which may contribute to phenotypic differences and developmental sensitivity of the ovarian follicle responses in SWR tumorsusceptible females at puberty.

Three previous mapping studies designed to identify genes associated with GC tumor development in SWR mice determined that tumor susceptibility is a polygenic trait involving multiple GC tumor $(G c t)$ susceptibility loci. The first mapping strategy examined the tumor susceptibility traits of 14 lines of the SWXJ RI strain set, which carry different homozygous chromosomal combinations of the progenitor SWR and SJL/Bm (hereafter SJL) inbred strains
(Svenson et al. 1995; Shultz et al. 1996). Female mice that retained spontaneous or androgen-induced GC tumor susceptibility always retained the SWR-derived Gctl locus on Chr 4 (Beamer et al. 1988b; Tennent et al. 1993). It was also determined from the SWXJ strain set that the influence of DHEA at $G c t l$ is genetically distinguishable from the action of testosterone at Gct4 on Chr X, suggesting that Gctl is a discrete target for DHEA in female mice that carry the $G c t 1^{S W}$ alleles (Beamer et al. 1988b). An $\mathrm{F}_{2}$ intercross mapping study using the SWXJ RI parental strains SWR and SJL confirmed significant linkage of GC tumor susceptibility with SWR alleles at $G c t 1$ on Chr 4, along with Gct2 on Chr 12, Gct3 on Chr 15, and Gct5 on Chr 9, and confirmed the modifier influence of SJL alleles at Gct4 on Chr X (Beamer et al. 1998). To improve genetic resolution, an $\mathrm{N}_{2} \mathrm{~F}_{1}$ backcross mapping strategy between the GC tumorsusceptible SWXJ-9 RI strain and the evolutionarily divergent Mus musculus castaneus (CAST) strain confirmed Gct1 as the fundamental locus for tumor initiation contributed by SWR and identified three novel autosomal loci, Gct7 on $\mathrm{Chr}$ 1, Gct8 on Chr 2, and Gct9 on Chr 13, and two epistatic interactions between loci on Chrs 17 and 18 and between loci on Chrs 2 and 10 (Dorward et al. 2005). In this backcross, tumor susceptibility alleles were consistently contributed by the Swiss-derived strains (SWR or SJL) that contribute to the SWXJ-9 genome, with no GC tumor susceptibility alleles contributed by the CAST strain.

The required contribution of SWR-derived susceptibility alleles at Gctl $\left(G c t 1^{S W}\right)$ to support both spontaneous and androgen-induced GC tumorigenesis across strain backgrounds underscored the $G c t 1^{S W}$ allele as an essential driver for this complex and developmentally restricted ovarian tumor phenotype. To map Gctl independently from the other autosomal loci, we constructed a congenic mouse strain that has a SWR genomic complement with the exception of a homozygous Chr 4 segment derived from the CAST strain in the region of Gctl. The congenic line was resistant to GC tumor development under androgenic influence, and therefore it was useful to support a subcongenic mapping strategy to refine the interval harboring Gctl. In this report, we present a high-resolution genetic map for the Gctl ovarian tumor susceptibility locus and a list of candidate genetic determinants for early-onset GC tumorigenesis.

\section{Materials and methods}

Mouse housing and nutrition

Mice were maintained in the specific-pathogen-free barrier facility in the Faculty of Medicine at Memorial University of Newfoundland and housed under a 12:12-h light/dark cycle. All mice were provided Laboratory Autoclavable 
Rodent Diet 5010 food $(27.5 \%$ protein, $13.5 \%$ fat, $59 \%$ carbohydrate; PMI Nutrition International, Richmond, IN, USA) and autoclaved water ad libitum. Females were weaned at 20-23 days of age and housed in groups of two to five animals per cage, which were $27.9 \mathrm{~cm}(\mathrm{~L}) \times 17.8 \mathrm{~cm}$ (W) $\times 12.7 \mathrm{~cm}(\mathrm{H})$ with high-profile filtered lids and contained sterilized Bed-O-Cobs ${ }^{\circledR}$ corn-cob bedding material (The Andersons, Maumee, OH, USA). All animal procedures were approved by the Institutional Animal Care Committee of Memorial University of Newfoundland.

\section{SWR.SJL-X.CAST-4 congenic strain development}

SWR.SJL- $\mathrm{X}_{5}$ is a previously reported congenic strain that carries the $G c t 1^{S W}$ alleles on Chr 4 and Gct4 alleles on Chr X derived from the SJL strain (Beamer et al. 1998; Dorward et al. 2003). SWR.SJL-X 5 female mice exhibit increased penetrance for spontaneous GC tumor initiation $(\sim 20 \%)$ with the same pubertal initiation timing as SWR females, without the requirement for exogenous androgen administration. A large segment of Chr 4 from the CAST strain was transferred onto the SWR.SJL- $\mathrm{X}_{5}$ congenic strain background through ten consecutive backcross generations followed by brother-sister intercross generations to create the unique strain SWR.SJL-X.CAST-4T (hereafter Line 4-T). The CAST homozygous donor segment of Line 4-T spans the region D4Mit31-D4Mit256, a $47.6 \times 10^{6}$-bp interval that includes the confidence intervals previously determined for the Gctl locus (Beamer et al. 1998; Dorward et al. 2003). The polymorphic CAST strain was chosen as a donor strain in the congenic mapping scheme to facilitate high-resolution genetic mapping of Gctl. The $\mathrm{N}_{10}$ backcross scheme also replenished the SWR.SJL-X $\mathrm{X}_{5}$ genomic background (estimated return of $>99 \%$ host genomic material). Established mating pairs of Line 4-T were confirmed to possess SWR allelic background at other mapped Gct susceptibility loci on Chrs 9, 12, and 15 and SJL allelic background at Gct4. Recombinant subcongenic lines were produced by mating Line 4-T females with SWR.SJL-X ${ }_{5}$ males to produce progeny heterozygous for CAST and SWR on Chr 4 between D4Mit31 and D4Mit256. Subsequent backcrossing to SWR.SJL- $\mathrm{X}_{5}$ generated $\mathrm{N}_{2} \mathrm{~F}_{1}$ mice with unique combinations of the CAST and SWR genomes across the Gctl locus via meiotic recombination. Selected recombinants were chosen as founders for nested and overlapping subcongenic lines that were fixed to homozygosity through brother-sister matings prior to phenotype assessment for GC tumor susceptibility.

\section{Phenotyping}

Granulosa cell tumor initiation is a spontaneous, lowpenetrance trait in female SWR mice that is sensitive to the androgenic environment (Beamer et al. 1985). Both DHEA and testosterone treatments increase trait penetrance in SWR females and GC tumor-susceptible SWXJ strains with the expectation for different genetic targets on $\mathrm{Chr} 4$ and $\mathrm{Chr} \mathrm{X}$, respectively (Beamer et al. 1988b). To test the GC tumor initiation phenotype of Line 4-T females, DHEA or testosterone was administered to prepubertal females (age = 20-24 days) in the form of a subcutaneous capsule. DHEA (5-androsten-3 $\beta$-ol-17-one) or testosterone (4-androsten17 $\beta$-ol-3-one) (Steraloids Inc., Newport, RI, USA) was packed into $1.0-\mathrm{cm}$ capsules made from Silastic tubing (1.98-mm inner diameter $\times$ 3.18-mm outer diameter; Dow Corning, Midland, MI, USA) capped with glass beads, as previously described (Beamer et al. 1988a). Capsules were implanted subcutaneously on the back at the time of weaning under isoflurane anesthesia (Baxter Corporation, Mississauga, ON, Canada) with postoperative carprofen $(5 \mathrm{mg} / \mathrm{kg}$ body weight [bw]) analgesic (Pfizer Canada, Kirkland, QC, Canada). For phenotypic examination, female mice were necropsied at 8 weeks of age and ovaries were examined for GC tumors. At this age, tumors present as unilateral or bilateral, cystic or solid hemorrhagic masses of 5-10 $\mathrm{mm}^{3}$ that are macroscopically identifiable. Females with either unilateral or bilateral GC tumors were counted as one affected animal. Following confirmation of the GC tumorresistant phenotype in Line 4-T females, all subcongenic line females were administered the DHEA capsule treatment to categorize the lines as tumor-susceptible or tumor-resistant.

\section{Genotyping}

Genomic DNA isolated from tail tip biopsy was genotyped with a series of 22 SSLP markers around Gct1 using a MasterTaq Kit (5 PRIME Inc., Gaithersburg, MD, USA). Each PCR reaction contained $7.3 \mu \mathrm{L}$ of distilled water, 1 $\mu \mathrm{L}$ of $5 \times$ TaqMaster PCR Enhancer heated to $65^{\circ} \mathrm{C}, 1 \mu \mathrm{L}$ of $10 \times$ Reaction Buffer, $0.2 \mu \mathrm{L}$ of $10 \mathrm{mM} \mathrm{dNTPs}$ (Invitrogen, Carlsbad, CA, USA), $0.22 \mu \mathrm{L}$ each of $10 \mu \mathrm{M}$ forward and reverse primers (Integrated DNA Technologies, Coralville, IA, USA), $0.05 \mu \mathrm{L}$ of Taq DNA polymerase, and $1 \mu \mathrm{L}$ of DNA template. PCR conditions were as follows: $97{ }^{\circ} \mathrm{C}$ for $30 \mathrm{~s}$; 39 cycles of $94{ }^{\circ} \mathrm{C}$ for $15 \mathrm{~s}$, $55^{\circ} \mathrm{C}$ for $30 \mathrm{~s}$, and $72{ }^{\circ} \mathrm{C}$ for $30 \mathrm{~s} ; 72{ }^{\circ} \mathrm{C}$ for $10 \mathrm{~min}$. Informative markers were determined using the Mouse Genome Database (Eppig et al. 2012) and included D4Mit31, D4Mit279, D4Mit70, D4Mit148, D4Mit179, D4Mit13, D4Mit126, D4Mit160, D4Mit232, D4Mit233, D4Mit206, D4Mit129, D4Mit49, D4Mit362, D4Mit127, D4Mit190, D4Mit208, and D4Mit256. PCR-based DNA markers were also designed in-house around novel SSLPs: D4sjh19 (5'-GTG GGG AGC ATG TCC TTA AA and 5'-TGG GAG TGT GTA GCA GAG GA), D4sjh10 (5'-GCA GAA ATG GCA CAG GAG AT and 5'-CCC ACA TTT GAA ACC ACC TC), D4sjh12 (5'-TTT GGA GAC CAA 
AGA TGA GAC A and 5'-CTT TTC TGG CCT CTG ACC TG), and D4sjhl3 (5'-TCT GGT TTC TAT GCG TGT GC and 5'-CGG GAT CCA TAT GGT AGT GG). SSLP PCR products were separated by horizontal electrophoresis in $4 \%$ MetaPhor agarose slab gels (Lonza, Rockland, ME, USA). The bands were visualized by ethidium bromide staining and were photographed for allele scoring purposes.

To facilitate fine mapping of Gctl, additional genetic polymorphisms between the CAST and SWR genomes were determined to supplement annotated DNA markers. Primer sequences were designed around known single nucleotide polymorphisms (SNPs) annotated in dbSNP (Sherry et al. 2001), or made use of unique SNPs identified during preliminary candidate gene sequencing (Supplementary Table 1). Because the SWR strain sequence is not publicly available, annotated SNPs were chosen on the basis of differences between CAST alleles and the alleles of other common inbred strains, particularly Swiss-derived strains that are phylogenetically related to SWR (Petkov et al. 2004). Each PCR reaction contained $22.5 \mu \mathrm{L}$ of Accuprime ${ }^{\mathrm{TM}} \mathrm{Pfx}$ Supermix, $0.25 \mu \mathrm{L}$ each of $10 \mu \mathrm{M}$ forward and reverse primers, and $2 \mu \mathrm{L}$ of salt-extracted kidney DNA template. PCR conditions were as follows: $95^{\circ} \mathrm{C}$ for $5 \mathrm{~min} ; 35$ cycles of $95{ }^{\circ} \mathrm{C}$ for $15 \mathrm{~s}, 55^{\circ} \mathrm{C}$ for $30 \mathrm{~s}$, and $68^{\circ} \mathrm{C}$ for $45 \mathrm{~s} ; 72{ }^{\circ} \mathrm{C}$ for $10 \mathrm{~min}$. The amplicons were sequenced in both directions using a BigDye Terminator v3.1 Cycle Sequencing Kit (Applied Biosystems, Foster City, CA, USA), on a 3730 DNA Analyzer and aligned with published sequences using Sequencher ver. 4.10.1 (Gene Codes Corporation, Ann Arbor, MI, USA).

\section{Statistical analysis}

A sufficient sample size per subcongenic line was determined to be 50 individual females based on statistical power calculations using an estimated DHEA-induced GC tumor incidence of $20 \%$ in susceptible lines relative to a tumor-resistant phenotype of $0 \%$ (Beamer et al. 1988b). Type I and Type II error probabilities were set to $\alpha=0.05$ and $\beta=0.20$, respectively. The GC tumor incidence of each subcongenic line was individually compared to the SWR inbred line incidence using the $\chi^{2}$ analysis for proportions, with a chosen significance level of $P<0.05$. All statistical analyses were performed with GraphPad Prism ver. 5.00 (GraphPad Software, San Diego, CA, USA).

\section{Results}

GC tumor incidence in SWR.SJL-X.CAST-4 founder congenic and subcongenic lines

Following the construction of the homozygous congenic Line 4-T, female mice were tested for GC tumor susceptibility under the influence of testosterone or DHEA, as per previous studies with SWR inbred and SWXJ RI strain females. Neither DHEA nor testosterone administration in the form of subcutaneous capsule implants triggered GC tumor development in Line 4-T females (Table 1). In direct contrast, SWR females exhibited a GC tumor incidence of $18 \%$ with DHEA capsule administration, in keeping with historical incidence following androgen supplementation in the diet (Table 1; Beamer et al. 1993). The GC tumor-resistant phenotype of Line 4-T females provided two key findings in support of the chosen congenic mapping strategy to resolve Gct1: (1) confirmation that the transferred genomic segment from the CAST strain encompassed the Gctl locus, such that the $G c t 1^{S W}$ tumor susceptibility alleles were replaced by $G c t 1^{C A}$ resistance alleles, and (2) confirmation that $G c t 1^{S W}$ is the driver for the ovarian GC tumor susceptibility phenotype, despite the accumulated genetic evidence for multiple genetic modifiers of susceptibility on Chr X and several autosomes.

Twelve informative SWR.SJL-X.CAST-4 recombinant subcongenic lines (Lines 4-1 through 4-12), with unique recombinations of the $G c t 1^{S W}$ and $G c t 1^{C A}$ alleles across the Gct1 locus, were successfully derived from the founder congenic Line 4-T and tested for GC tumor susceptibility with subcutaneous DHEA-filled capsules. The genotypes of the individual lines across the Gctl interval and the phenotype results for the groups of females examined for each line are represented in Fig. 1. Females from Lines 4-7 through 4-12 were GC tumor susceptible compared to Lines 4-1 through 4-6, which are GC tumor-resistant and therefore phenocopy Line 4-T. GC tumor incidences of the individual susceptible Lines 4-7 through 4-12 (18, 11, 19, 18,27 , and $16 \%$, respectively) were not different from SWR females treated with the same lot of DHEA $(18 \%)$, while the lines with a resistant phenotype $(0 \%)$ were significantly different $(P<0.0001)$. This indicates that the Line 4-T recombinant subcongenic Lines 4-7 through 4-12 carry the $G c t 1^{S W}$ alleles, whereas Lines 4-1 through 4-6 retain the donor $G c t 1^{C A}$ tumor-resistance alleles. The phenotype-driven mapping process refined the Gctl ${ }^{S W}$ locus to lie between rs27633106 and D4knsl, a $1.31 \times 10^{6}$-bp interval defined by Line $4-10$ at the proximal boundary and Lines 4-5 and 4-6 at the distal boundary. Of note, Line 4-7 was found to be heterozygous for SWR and CAST alleles in the region between markers D4Mit70

Table 1 Granulosa cell tumor incidence in SWR and Line 4-T female mice treated with testosterone or DHEA at puberty

\begin{tabular}{lll}
\hline Strain & Testosterone & DHEA \\
\hline SWR & $21 / 121(17 \%)^{\mathrm{a}}$ & $9 / 51(18 \%)$ \\
Line 4-T & $0 / 50(0 \%)$ & $0 / 52(0 \%)$ \\
\hline
\end{tabular}

${ }^{\text {a }} 0.1 \%$ testosterone diet supplement (Beamer et al. 1993) 
and D4Mit179 following fine-genotyping, but this region did not interfere with the Gctl boundary determinations.

Short list of candidate genes for the Gctl tumor susceptibility locus

The $1.31 \times 10^{6}$-bp Gctl interval contains 16 unique annotated genetic determinants, including 10 proteincoding genes, 2 processed transcripts, 4 noncoding RNA genes, and 23 pseudogenes (Ensembl Mouse Genome Browser release 67; NCBI m37 May 2012; Flicek et al. 2012). The majority of the annotated features are located at the distal end of the Gctl interval, which is particularly pseudogene-rich and contains repetitive genetic elements. Table 2 summarizes the features of the 16 annotated genes in the Gctl interval.

\section{Discussion}

Granulosa cell tumors of the sex cord-stromal class can affect women at either end of the reproductive spectrum and have generally been classified as adult- or juvenile-type based on age of onset and histology. The latest classification paradigm incorporates molecular genetic strategies, with the report of a specific association for a somatic missense (p.C134W) mutation in the FOXL2 transcription factor in adult human GC tumors (Schrader et al. 2009; Shah et al. 2009). FOXL2 is a member of the forkhead/hepatocyte nuclear factor 3 gene family, which is involved in normal ovarian development and GC differentiation in several species (Pisarska et al. 2011). The mechanism of the p.C134W FOXL2 somatic mutation to support adult-type GC tumorigenesis is under investigation (Benayoun et al. 2010; D'Angelo et al. 2011; L'Hôte et al. 2012), but the curious lack of association of this genetic variant with juvenile-type GC tumors of the ovary supports the likelihood for an alternate genetic etiology in juvenile cases. Identification of Gctl in the SWR mouse model would provide another avenue of genetic investigation for juveniletype GC tumors in human patients that may be dependent or independent of FOXL2 activity.

Granulosa cell tumorigenesis in the SWR mouse recapitulates inherent susceptibility to early-onset GC tumors,
Fig. 1 Haplotypes and GC tumor susceptibility in SWR.SJL-X.CAST founder and congenic subline females. Females from the SWR.SJLX.CAST congenic sublines 4-7 through 4-12 have significantly increased GC tumor incidence compared with individuals from line 4-T and lines 4-1 through 4-6 $(P<0.0001)$. Tumorsusceptible strains share common regions of SWR genetic background between markers $r s 27633106$ and D4knsl, for a minimal $1.31 \times 10^{6}$-bp genetic interval containing Gct1 that is defined by line $4-10$ at the proximal boundary and lines 4-5 and 4-6 at the distal boundary. Line 4-7 was found to be heterozygous for SWR and CAST alleles in the region between markers D4Mit70 and D4Mit179 following phenotyping. However, the heterozygous region lies outside of the Gctl interval and does not influence tumorigenesis. $M b 10^{6}$-bp

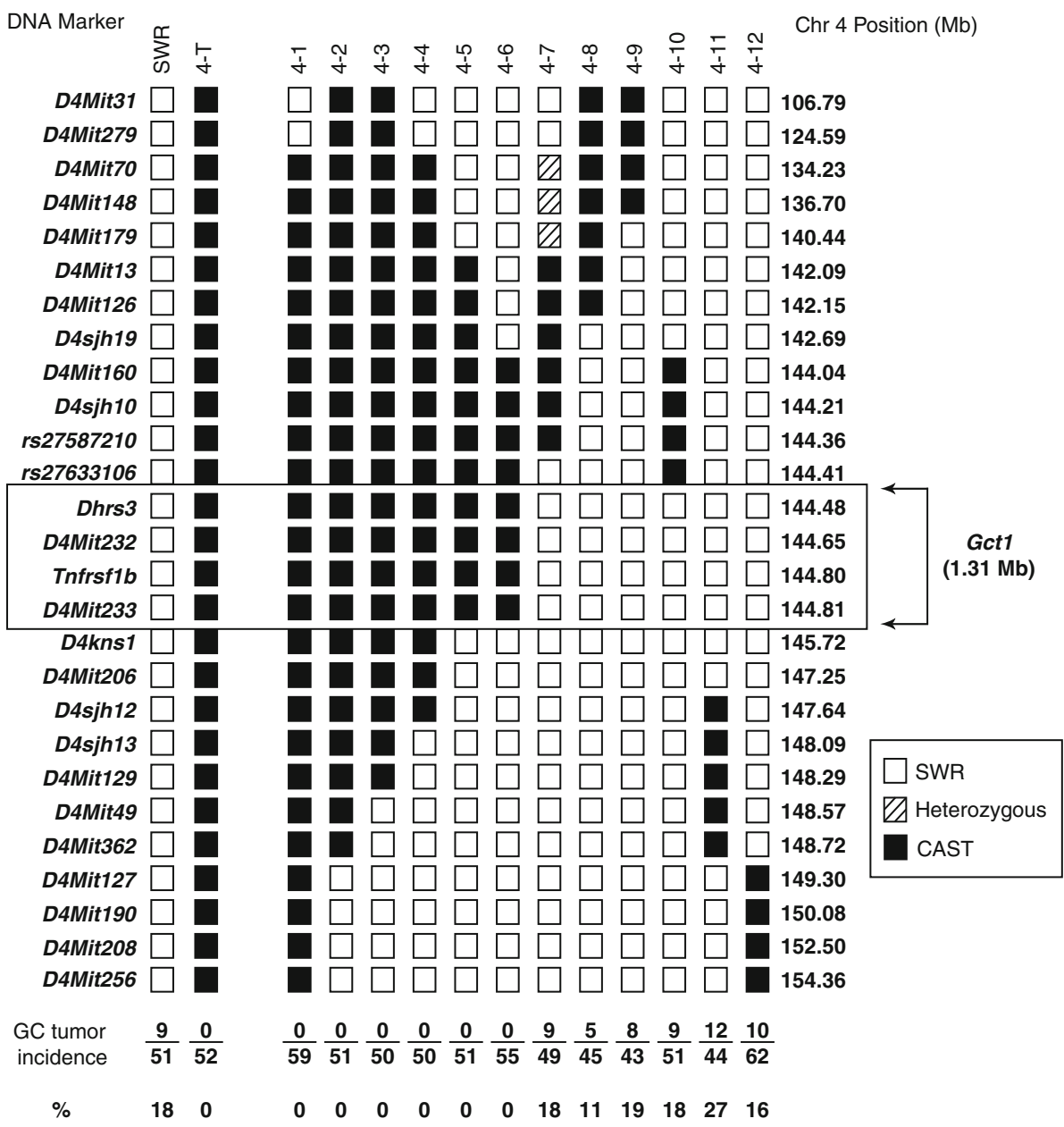


Table 2 Identity and features of the genetic determinants within the Gct1 interval

\begin{tabular}{|c|c|c|c|c|c|c|}
\hline Gene $^{a}$ & Description & Gene ontology & $\begin{array}{l}\text { Location } \\
\text { on chr } 4 \text { (bp) }\end{array}$ & Strand & $\begin{array}{l}\text { Gene } \\
\text { type }\end{array}$ & $\begin{array}{l}\text { No. unique } \\
\text { transcripts }\end{array}$ \\
\hline Dhrs3 & $\begin{array}{l}\text { Dehydrogenase/reductase } \\
\text { (SDR family) member } 3\end{array}$ & Oxidoreductase activity & $144,482,730$ & + & $\mathrm{PC}$ & 8 \\
\hline Vps13d & Vacuolar protein sorting $13 \mathrm{D}$ (yeast) & ND & $144,562,529$ & - & PC & 10 \\
\hline Tnfrsflb & $\begin{array}{l}\text { Tumor necrosis factor receptor } \\
\text { superfamily, member } 1 \mathrm{~b}\end{array}$ & TNF receptor & $144,803,366$ & - & $\mathrm{PC}$ & 2 \\
\hline Tnfrsf8 & $\begin{array}{l}\text { Tumor necrosis factor receptor } \\
\text { superfamily, member } 8\end{array}$ & TNF receptor & $144,857,040$ & - & $\mathrm{PC}$ & 2 \\
\hline Gm13227 & Predicted gene 13227 & ND & $145,000,148$ & + & NPT & 2 \\
\hline Gm13225 & Predicted gene 13225 & ND & $145,100,662$ & + & $\mathrm{PC}$ & 4 \\
\hline Gm13242 & Predicted gene 13242 & ND & $145,104,787$ & + & $\mathrm{PC}$ & 3 \\
\hline Gm13212 & Predicted gene 13212 & ND & $145,175,069$ & + & $\mathrm{PC}$ & 3 \\
\hline Gm17609 & Predicted gene 17609 & ND & $145,191,866$ & - & LINC & 1 \\
\hline Gm13236 & Predicted gene 13236 & ND & $145,352,832$ & + & LINC & 1 \\
\hline AL929465.1 & - & ND & $145,454,975$ & + & NMI & 1 \\
\hline Gm13235 & Predicted gene 13235 & ND & $145,458,697$ & + & $\mathrm{PC}$ & 2 \\
\hline Gm13248 & Predicted gene 13248 & ND & $145,539,879$ & - & $\mathrm{PC}$ & 2 \\
\hline 1700095A21Rik & RIKEN cDNA 1700095A21Rik gene & ND & $145,651,166$ & + & AS & 1 \\
\hline Gm13247 & Predicted gene 13247 & ND & $145,658,647$ & - & PC & 2 \\
\hline Gm17565 & Predicted gene 17565 & ND & $145,686,275$ & + & LINC & 1 \\
\hline
\end{tabular}

$A S$ novel antisense, LINC lincRNA, $P C$ protein coding, $N D$ not determined, NMI novel miRNA, NPT novel processed transcript, + forward, reverse

${ }^{a}$ Excluded from this list are the 23 known pseudogenes present within the Gct1 interval

and genetic investigations for this polygenic ovarian trait has identified Gctl on distal mouse $\mathrm{Chr} 4$ as a fundamental locus for GC tumor initiation during the restricted window of susceptibility at the pubertal transition. This study employed a subcongenic mapping strategy to refine the Gctl locus using androgen supplementation to increase trait penetrance. DHEA administration facilitated genetic mapping of Gctl and reinforced the extent of steroid hormone influence upon the mechanism of GC tumor initiation in the mammalian ovary.

Previous mapping studies were unable to resolve the Gctl interval to a practical list of candidate genes, despite strong genetic evidence for the existence of a unique tumorigenic driver determinant on distal Chr 4 in the SWR strain. The congenic mapping strategy described herein has resolved Gct 1 to a $1.31 \times 10^{6}$-bp interval, a defined candidate gene list, and a congenic strain resource for mechanistic studies related to early-onset GC tumorigenesis. The refinement of Gctl was aided by the empirical identification of novel SSLP- and SNP-based genotyping DNA markers that are polymorphic between SWR and CAST strains because the published DNA marker resources had been exhausted. The $1.31 \times 10^{6}$-bp interval currently contains annotations for 16 known protein-coding genes, known and novel processed transcripts, noncoding RNA genes, and 23 annotated pseudogenes. Until Gctl is identified and validated, all DNA polymorphisms unique to the SWR strain within the mapped Gctl interval are under consideration as causative of the trait. In SWR mice, the DHEA-responsive nature of the Gctl locus is an opportunity to further interrogate the list of candidate genes; however, no candidate genes within the narrowed interval are currently known to be responsive to DHEA in terms of gene expression or ligand-binding activities.

Four characterized protein-coding genes within the Gct1 interval are conserved between mouse and human based on current genome annotations: Vps13d, Tnfrsf8, Tnfrsflb, and Dhrs3. Given our hypothesis that mouse GC tumor-susceptibility candidates will provide translational information for juvenile-onset GC tumors of the ovary in young female patients, these genes have been given priority for further investigation based on sequence and expression analysis. A comparison of fully differentiated tissue-specific expression patterns is available for these four candidates based on the Gene Expression Atlas initiative (Su et al. 2004) accessed through the BioGPS web portal (www.biogps.gnf.org; Wu et al. 2009). The four genes show evidence of expression in both the mouse and the human ovary, in agreement with our qualitative transcript assessment in the SWR mouse ovary (data not shown). Since it is our goal to identify the 
mechanism of GC tumorigenesis in the SWR mouse, these genes are of significant interest, given their reported biological functions and relevant expression patterns.

Vps $13 d$ is a complex mouse gene with multiple isoforms. It has not been well characterized but is a member of the vacuolar-protein-sorting 13 (VPS13) gene family that is conserved across several species. In yeast, VPS proteins are involved in the trafficking of membrane proteins between the trans-Golgi network and the prevacuolar compartment. Velayos-Baeza et al. (2004) predicted through in silico analyses that the human VPS13D protein may have two putative domains: a ubiquitin-associated domain that confers protein target specificity in the ubiquitination pathway (Hofmann and Bucher 1996), and a ricin-B-lectin domain, which is present in many carbohydrate-recognition proteins and can bind simple sugars (Hazes 1996). It is hypothesized that if these putative domains are present, VPS13D is involved in the trafficking of ubiquitin-tagged proteins and/ or carbohydrates (Velayos-Baeza et al. 2004).

Tnfrsf8 is a member of the TNF-receptor superfamily which is expressed mainly in activated cells of the immune system (Berro et al. 2004). Tnfrsf8 signaling can have proliferative and survival or antiproliferative and apoptotic effects depending on the cellular and stimulatory context (Gruss et al. 1994; Mir et al. 2000). Serum Tnfrsf8 levels have been found to be increased in patients with autoimmune diseases and those infected with hepatitis B, hepatitis C, Epstein-Barr, and HIV, and Tnfrsf8 expression is upregulated in hematological malignancies, including Hodgkin's and non-Hodgkin's lymphomas (reviewed by Oflazoglu et al. 2009).

Tnfrsf $1 b$, a member of the TNF-receptor superfamily, is a type I transmembrane receptor that binds tumor necrosis factor alpha (TNF $\alpha)$. Tnfrsf $1 b$ contains a short, C-terminal intracellular region that is involved in binding TNF receptor associated factor 2 (TRAF2). TRAF2 binding triggers the recruitment of cellular inhibitor of apoptosis 1 (c-IAP1) and c-IAP2, which leads to Jun N-terminal kinase and NF-кB activation (reviewed by Carpentier et al. 2004). When signaling through Tnfrsf $1 \mathrm{~b}$, TNF $\alpha$ negatively regulates ovarian folliculogenesis, as Tnfrsflb-null mice had increased numbers of growing follicles compared to strain controls (Greenfeld et al. 2007); however, it is not clear if this is through an alteration of follicle growth rate, reduced follicular atresia, or some other mechanism. In humans, the p.M196R TNFRSF1B variant has been associated with hyperandrogenism and polycystic ovary syndrome in women (Peral et al. 2002). An established role for Tnfrsflb in the ovary and its activation of pathways resulting in proliferation and cell survival strengthen its standing as a candidate for Gctl and the existence of a unique allele in the SWR strain.

The Dhrs3 gene encodes a short-chain dehydrogenase/ reductase that is induced by retinoic acid and reduces all-trans-retinal, a storage form of vitamin A, in a process necessary for photoreception (Haeseleer et al. 1998; Cerignoli et al. 2002). Dhrs3 is expressed in multiple differentiated tissues besides the retina, and DHRS 3 expression has been found to be upregulated in human papillary thyroid carcinomas, although it is negatively correlated with subsequent lymph node metastasis (Oler et al. 2008). Dhrs3 was found to be a downstream target of bone morphogenic protein 2 , a TGF $\beta$ family member expressed in GCs of antral follicles that regulates follicle-stimulating hormone receptor and aromatase expression and the prevention of premature follicle luteinization (Bachner et al. 1998; Shi et al. 2011). Dhrs 3 is under investigation as a candidate for shared identity with $G c t 1$, as we continue to examine all candidate genes in the interval using a whole-locus customized sequencing approach, gene expression analysis, and in vivo functional strategies in GC tumor-susceptible SWR mice. We anticipate that the combination of strategies will reveal unique SWR polymorphisms, the endocrine-sensitive tumorigenic mechanism, and an explanation for trait sensitivity to DHEA.

The SWR mouse model for GC tumorigenesis is a unique and realistic model for genetically complex and stochastic cancer risk and a well-described model for juvenile GC tumors in pediatric patients. Pursuit of GC tumor susceptibility genes in the mouse will provide specific candidates for further investigation in juvenile GC tumor cases to elucidate a genetic etiology for this unique ovarian tumor class. The interval for Gctl is orthologous to human Chr 1p36.22, a region that has been implicated in a number of disorders through genome-wide association and cytogenetic studies. Kreisel et al. (2011) identified copy number alterations at $\mathrm{Chr} 1 \mathrm{p} 36.22$ in a subset of diffuse large B-cell lymphomas, an aggressive form of nonHodgkin's lymphoma. Human Chr 1p36.22 has also been identified as a region frequently lost in human hepatocellular carcinoma (Nishimura et al. 2006) and is a susceptibility locus for hepatocellular carcinoma in patients with hepatitis B virus infection (Zhang et al. 2010). Deletions at human Chr 1p36.22 are also frequent in infiltrating ductal carcinoma of the breast (Hawthorn et al. 2010) and premenopausal breast cancers (Varma et al. 2005). Loss of heterozygosity at the $\mathrm{Chr} 1 \mathrm{p} 36.2$ region is associated with neuroblastoma (Mora et al. 2000), and multiple putative tumor suppressor genes within the same region have been identified (Krona et al. 2004; Liu et al. 2011). Despite these associations, Chr 1p36.22 has not been linked with adultor juvenile-type GC tumor susceptibility, although the rarity of cases in the human population has precluded genetic linkage studies. The identification of Gctl in the mouse model will permit cross-examination of the role for this ovarian GC tumor susceptibility allele in other malignancies genetically associated with Chr 1p36.22. 
Acknowledgments This work was performed at two institutions: The Jackson Laboratory (TJL) and Memorial University of Newfoundland (MUN). The founder congenic line development was supported at TJL by a NCI Cancer Core Grant CA34196 (WGB). Congenic subline development and phenotyping at MUN was supported by the Canadian Institutes of Health Research (CIHR), the Newfoundland and Labrador Department of Innovation, Trade \& Rural Development, Canada Foundation for Innovation, and the Canada Research Chairs program (AMD). KNS received fellowship support from the Faculty of Medicine and School of Graduate Studies (MUN) and the CIHR.

Open Access This article is distributed under the terms of the Creative Commons Attribution License which permits any use, distribution, and reproduction in any medium, provided the original author(s) and the source are credited.

\section{References}

Al-Agha OM, Huwait HF, Chow C, Yang W, Senz J, Kalloger SE, Huntsman DG, Young RH, Gilks CB (2011) FOXL2 is a sensitive and specific marker for sex cord-stromal tumors of the ovary. Am J Surg Pathol 35:484-494

Bachner D, Ahrens M, Schroder D, Hoffmann A, Lauber J, Betat N, Steinert P, Flohe L, Gross G (1998) Bmp-2 downstream targets in mesenchymal development identified by subtractive cloning from recombinant mesenchymal progenitors (C3H10T1/2). Dev Dyn 213:398-411

Beamer WG, Hoppe PC, Whitten WK (1985) Spontaneous malignant granulosa cell tumors in ovaries of young SWR mice. Cancer Res 45:5575-5581

Beamer WG, Shultz KL, Tennent BJ (1988a) Induction of ovarian granulosa cell tumors in SWXJ-9 mice with dehydroepiandrosterone. Cancer Res 48:2788-2792

Beamer WG, Tennent BJ, Shultz KL, Nadeau JH, Shultz LD, Skow LC (1988b) Gene for ovarian granulosa cell tumor susceptibility, Gct, in SWXJ recombinant inbred strains of mice revealed by dehydroepiandrosterone. Cancer Res 48:5092-5095

Beamer WG, Shultz KL, Tennent BJ, Shultz LD (1993) Granulosa cell tumorigenesis in genetically hypogonadal-immunodeficient mice grafted with ovaries from tumor-susceptible donors. Cancer Res 53:3741-3746

Beamer WG, Shultz KL, Tennent BJ, Nadeau JH, Churchill GA, Eicher EM (1998) Multigenic and imprinting control of ovarian granulosa cell tumorigenesis in mice. Cancer Res 58:3694-3699

Benayoun BA, Caburet S, Dipietromaria A, Georges A, D'Haene B, Pandaranayaka PJ, L'Hôte D, Todeschini AL, Krishnaswamy S, Fellous M, De Baere E, Veitia RA (2010) Functional exploration of the adult ovarian granulosa cell tumor-associated somatic FOXL2 mutation p.Cys134Trp (c.402C >G). PLoS One 5:e8789

Berro AI, Perry GA, Agrawal DK (2004) Increased expression and activation of CD30 induce apoptosis in human blood eosinophils. J Immunol 173:2174-2183

Björkholm E, Silfverswärd C (1981) Prognostic factors in granulosacell tumors. Gynecol Oncol 11:261-274

Carpentier I, Coornaert B, Beyaert R (2004) Function and regulation of tumor necrosis factor receptor type 2. Curr Med Chem 11:2205-2212

Cerignoli F, Guo X, Cardinali B, Rinaldi C, Casaletto J, Frati L, Screpanti I, Gudas LJ, Gulino A, Thiele CJ, Giannini G (2002) retSDR1, a short-chain retinol dehydrogenase/reductase, is retinoic acid-inducible and frequently deleted in human neuroblastoma cell lines. Cancer Res 62:1196-1204
D’Angelo E, Mozos A, Nakayama D, Espinosa I, Catasus L, Munoz J, Prat J (2011) Prognostic significance of FOXL2 mutation and mRNA expression in adult and juvenile granulosa cell tumors of the ovary. Mod Pathol 24:1360-1367

Dorward AM, Shultz KL, Ackert-Bicknell CL, Eicher EM, Beamer WG (2003) High-resolution genetic map of X-linked juveniletype granulosa cell tumor susceptibility genes in mouse. Cancer Res 63:8197-8202

Dorward AM, Shultz KL, Horton LG, Li R, Churchill GA, Beamer WG (2005) Distal Chr 4 harbors a genetic locus (Gctl) fundamental for spontaneous ovarian granulosa cell tumorigenesis in a mouse model. Cancer Res 65:1259-1264

Dorward AM, Shultz KL, Beamer WG (2007) LH analog and dietary isoflavones support ovarian granulosa cell tumor development in a spontaneous mouse model. Endocr Relat Cancer 14:369-379

Eppig JT, Blake JA, Bult CJ, Kadin JA, Richardson JE, Mouse Genome Database Group (2012) The mouse genome database (MGD): comprehensive resource for genetics and genomics of the laboratory mouse. Nucleic Acids Res 40:D881-D886

Flicek P, Amode MR, Barrell D, Beal K, Brent S, Carvalho-Silva D, Clapham P, Coates G, Fairley S, Fitzgerald S, Gil L, Gordon L, Hendrix M, Hourlier T, Johnson N, Kahari AK, Keefe D, Keenan S, Kinsella R, Komorowska M, Koscielny G, Kulesha E, Larsson P, Longden I, McLaren W, Muffato M, Overduin B, Pignatelli M, Pritchard B, Riat HS, Ritchie GR, Ruffier M, Schuster M, Sobral D, Tang YA, Taylor K, Trevanion S, Vandrovcova J, White S, Wilson M, Wilder SP, Aken BL, Birney E, Cunningham F, Dunham I, Durbin R, Fernandez-Suarez XM, Harrow J, Herrero J, Hubbard TJ, Parker A, Proctor G, Spudich G, Vogel J, Yates A, Zadissa A, Searle SM (2012) Ensembl 2012. Nucleic Acids Res 40:D84-D90

Gocze PM, Beamer WG, de Jong FH, Freeman DA (1997) Hormone synthesis and responsiveness of spontaneous granulosa cell tumors in $(\mathrm{SWR} \times \mathrm{SWXJ}-9)$ F1 mice. Gynecol Oncol 65: 143-148

Greenfeld CR, Roby KF, Pepling ME, Babus JK, Terranova PF, Flaws JA (2007) Tumor necrosis factor (TNF) receptor type 2 is an important mediator of TNF alpha function in the mouse ovary. Biol Reprod 76:224-231

Gruss HJ, Boiani N, Williams DE, Armitage RJ, Smith CA, Goodwin RG (1994) Pleiotropic effects of the CD30 ligand on CD30expressing cells and lymphoma cell lines. Blood 83:2045-2056

Haeseleer F, Huang J, Lebioda L, Saari JC, Palczewski K (1998) Molecular characterization of a novel short-chain dehydrogenase/reductase that reduces all-trans-retinal. J Biol Chem 273: 21790-21799

Hawthorn L, Luce J, Stein L, Rothschild J (2010) Integration of transcript expression, copy number and $\mathrm{LOH}$ analysis of infiltrating ductal carcinoma of the breast. BMC Cancer 10:460

Hazes B (1996) The (QxW)3 domain: a flexible lectin scaffold. Protein Sci 5:1490-1501

Hofmann K, Bucher P (1996) The UBA domain: a sequence motif present in multiple enzyme classes of the ubiquitination pathway. Trends Biochem Sci 21:172-173

Kreisel F, Kulkarni S, Kerns RT, Hassan A, Deshmukh H, Nagarajan R, Frater JL, Cashen A (2011) High resolution array comparative genomic hybridization identifies copy number alterations in diffuse large B-cell lymphoma that predict response to immunochemotherapy. Cancer Genet 204:129-137

Krona C, Ejeskar K, Caren H, Abel F, Sjoberg RM, Martinsson T (2004) A novel 1p36.2 located gene, APITD1, with tumoursuppressive properties and a putative p53-binding domain, shows low expression in neuroblastoma tumours. $\mathrm{Br} \mathrm{J}$ Cancer 91: $1119-1130$

L'Hôte D, Georges A, Todeschini AL, Kim JH, Benayoun BA, Bae J, Veitia RA (2012) Discovery of novel protein partners of the 
transcription factor FOXL2 provides insights into its physiopathological roles. Hum Mol Genet 21:3264-3274

Liu Z, Yang X, Li Z, McMahon C, Sizer C, Barenboim-Stapleton L, Bliskovsky V, Mock B, Ried T, London WB, Maris J, Khan J, Thiele CJ (2011) CASZ1, a candidate tumor-suppressor gene, suppresses neuroblastoma tumor growth through reprogramming gene expression. Cell Death Differ 18:1174-1183

Mir SS, Richter BW, Duckett CS (2000) Differential effects of CD30 activation in anaplastic large cell lymphoma and Hodgkin disease cells. Blood 96:4307-4312

Mora J, Cheung NK, Kushner BH, LaQuaglia MP, Kramer K, Fazzari M, Heller G, Chen L, Gerald WL (2000) Clinical categories of neuroblastoma are associated with different patterns of loss of heterozygosity on chromosome arm 1p. J Mol Diagn 2:37-46

Mork L, Maatouk DM, McMahon JA, Guo JJ, Zhang P, McMahon AP, Capel B (2012) Temporal differences in granulosa cell specification in the ovary reflect distinct follicle fates in mice. Biol Reprod 86(2):37

Nishimura T, Nishida N, Komeda T, Fukuda Y, Ikai I, Yamaoka Y, Nakao K (2006) Genome-wide semiquantitative microsatellite analysis of human hepatocellular carcinoma: discrete mapping of smallest region of overlap of recurrent chromosomal gains and losses. Cancer Genet Cytogenet 167:57-65

Oflazoglu E, Grewal IS, Gerber H (2009) Targeting CD30/CD30L in oncology and autoimmune and inflammatory diseases. Adv Exp Med Biol 647:174-185

Oler G, Camacho CP, Hojaij FC, Michaluart P Jr, Riggins GJ, Cerutti JM (2008) Gene expression profiling of papillary thyroid carcinoma identifies transcripts correlated with BRAF mutational status and lymph node metastasis. Clin Cancer Res 14:4735-4742

Peral B, San Millan JL, Castello R, Moghetti P, Escobar-Morreale HF (2002) Comment: the methionine 196 arginine polymorphism in exon 6 of the TNF receptor 2 gene (TNFRSF1B) is associated with the polycystic ovary syndrome and hyperandrogenism. J Clin Endocrinol Metab 87:3977-3983

Petkov PM, Ding Y, Cassell MA, Zhang W, Wagner G, Sargent EE, Asquith S, Crew V, Johnson KA, Robinson P, Scott VE, Wiles MV (2004) An efficient SNP system for mouse genome scanning and elucidating strain relationships. Genome Res 14:1806-1811

Pisarska MD, Barlow G, Kuo FT (2011) Minireview: roles of the forkhead transcription factor FOXL2 in granulosa cell biology and pathology. Endocrinology 152:1199-1208

Schrader KA, Gorbatcheva B, Senz J, Heravi-Moussavi A, Melnyk N, Salamanca C, Maines-Bandiera S, Cooke SL, Leung P, Brenton JD, Gilks CB, Monahan J, Huntsman DG (2009) The specificity of the FOXL2 c.402C $>$ G somatic mutation: a survey of solid tumors. PLoS One 4:e7988

Shah SP, Kobel M, Senz J, Morin RD, Clarke BA, Wiegand KC, Leung G, Zayed A, Mehl E, Kalloger SE, Sun M, Giuliany R, Yorida E, Jones S, Varhol R, Swenerton KD, Miller D, Clement PB, Crane C, Madore J, Provencher D, Leung P, DeFazio A, Khattra J, Turashvili G, Zhao Y, Zeng T, Glover JN, Vanderhyden B, Zhao C, Parkinson CA, Jimenez-Linan M, Bowtell DD, Mes-Masson AM, Brenton JD, Aparicio SA, Boyd N, Hirst M, Gilks CB, Marra M, Huntsman DG (2009) Mutation of FOXL2 in granulosa-cell tumors of the ovary. N Engl J Med 360:2719-2729
Sherry ST, Ward MH, Kholodov M, Baker J, Phan L, Smigielski EM, Sirotkin K (2001) dbSNP: the NCBI database of genetic variation. Nucleic Acids Res 29:308-311

Shi J, Yoshino O, Osuga Y, Koga K, Hirota Y, Nose E, Nishii O, Yano T, Taketani Y (2011) Bone morphogenetic protein-2 (BMP-2) increases gene expression of FSH receptor and aromatase and decreases gene expression of LH receptor and StAR in human granulosa cells. Am J Reprod Immunol 65:421-427

Shultz KL, Svenson KL, Cheah Y, Paigen B, Beamer WG (1996) Strain distribution pattern for SSLP markers in the SWXJ recombinant inbred strain set: chromosomes 7 to X. Mamm Genome 7:526-532

Sivasankaran S, Itam P, Ayensu-Coker L, Sanchez J, Egler RA, Anderson ML, Brandt ML, Dietrich JE (2009) Juvenile granulosa cell ovarian tumor: a case report and review of literature. J Pediatr Adolesc Gynecol 22:e114-e117

Su AI, Wiltshire T, Batalov S, Lapp H, Ching KA, Block D, Zhang J, Soden R, Hayakawa M, Kreiman G, Cooke MP, Walker JR, Hogenesch JB (2004) A gene atlas of the mouse and human protein-encoding transcriptomes. Proc Natl Acad Sci U S A 101:6062-6067

Svenson KL, Cheah YC, Shultz KL, Mu JL, Paigen B, Beamer WG (1995) Strain distribution pattern for SSLP markers in the SWXJ recombinant inbred strain set: chromosomes 1 to 6 . Mamm Genome 6:867-872

Tennent BJ, Shultz KL, Sundberg JP, Beamer WG (1990) Ovarian granulosa cell tumorigenesis in SWR-derived F1 hybrid mice: preneoplastic follicular abnormality and malignant disease progression. Am J Obstet Gynecol 163:625-634

Tennent BJ, Shultz KL, Beamer WG (1993) Genetic susceptibility for C19 androgen induction of ovarian granulosa cell tumorigenesis in SWXJ strains of mice. Cancer Res 53:1059-1063

Varma G, Varma R, Huang H, Pryshchepava A, Groth J, Fleming D, Nowak NJ, McQuaid D, Conroy J, Mahoney M, Moysich K, Falkner KL, Geradts J (2005) Array comparative genomic hybridisation $(\mathrm{aCGH})$ analysis of premenopausal breast cancers from a nuclear fallout area and matched cases from Western New York. Br J Cancer 93:699-708

Velayos-Baeza A, Vettori A, Copley RR, Dobson-Stone C, Monaco AP (2004) Analysis of the human VPS13 gene family. Genomics 84:536-549

Wu C, Orozco C, Boyer J, Leglise M, Goodale J, Batalov S, Hodge CL, Haase J, Janes J, Huss JW 3rd, Su AI (2009) BioGPS: an extensible and customizable portal for querying and organizing gene annotation resources. Genome Biol 10:R130

Young RH, Dickersin GR, Scully RE (1984) Juvenile granulosa cell tumor of the ovary. A clinicopathological analysis of 125 cases. Am J Surg Pathol 8:575-596

Zhang H, Zhai Y, Hu Z, Wu C, Qian J, Jia W, Ma F, Huang W, Yu L, Yue W, Wang Z, Li P, Zhang Y, Liang R, Wei Z, Cui Y, Xie W, Cai M, Yu X, Yuan Y, Xia X, Zhang X, Yang H, Qiu W, Yang J, Gong F, Chen M, Shen H, Lin D, Zeng YX, He F, Zhou G (2010) Genome-wide association study identifies 1 p36.22 as a new susceptibility locus for hepatocellular carcinoma in chronic hepatitis B virus carriers. Nat Genet 42:755-758 